ARTIGO

\title{
Formação de professores e currículo: questões em debate
}

\author{
Antonio Flavio Barbosa Moreira a
}

\section{Resumo}

O presente artigo traz uma análise teórica sobre a formação inicial docente e suas relações com o currículo. Busca-se, a partir dos argumentos levantados, configurar uma concepção de qualidade na escola e na formação docente, analisando a formação inicial de modo abrangente, para que se evitem parcialidades e fracionamentos. Como conclusões, aponta-se que essa formação não pode ser vista apenas como uma atividade prática, baseada na racionalidade instrumental, mas como atividade intelectual, pautada pelo exercício consciente da crítica e por uma postura humanista.

Palavras-chave: Formação de professores. Currículo. Humanismo.

\section{Introdução}

Neste texto, focalizo a formação inicial docente: tenho por propósito examinar princípios orientadores da organização e do funcionamento dos cursos que por ela respondem. Espero que os pontos de vista que defendo venham a configurar uma concepção de qualidade na escola e na formação docente.

Proponho-me, então, a examinar a formação inicial de modo abrangente, para que se evitem parcialidades e fracionamentos. Sustento que essa formação não pode ser vista apenas como uma atividade prática que vise, principalmente, a capacitar o docente a dominar técnicas e métodos a serem empregados, "com sucesso", nas salas de aula. Como bem acentua Pinar, "nossa era está encharcada de energia prática. Deixou de se importar com as ideias, só quer ação" (2003, p. 142). Da adesão a essa perspectiva, a meu ver, pode resultar a celebração da prática pela prática.

A adoção de um enfoque tão limitado, em que se supervalorizem o agir e a racionalidade instrumental, acaba contribuindo para que a formação de

\footnotetext{
a Universidade Federal do Rio de Janeiro, Rio de Janeiro, RJ, Brasil/Universidade Católica de Petrópolis, Petrópolis, RJ, Brasil.
} 
professores venha a se assemelhar aos locais de trabalho das grandes corporações e a se curvar às leis da economia e à mentalidade empresarial. Nesse caso, os sentidos mais globais e humanistas, que deveriam inspirar a formação, terminam substituídos por propósitos de controle de práticas, saberes, habilidades, atitudes, sentimentos e pensamentos.

Caminho, no presente texto, na contramão dessa tendência. Insisto em que se concebam a formação dos profissionais do magistério, assim como a prática pedagógica, como atividades intelectuais, pautadas pelo exercício consciente da crítica e por uma postura humanista. Não se trata de marcar a formação docente por "aprender a fazer bem algo novo"; a intenção é aprofundar a compreensão e aguçar a inteligência, a sensibilidade e o compromisso dos profissionais da Educação (PINAR, 2003).

Defendo a recuperação dos elos entre a estrutura interior do professor e a sua atuação no mundo, ou seja, entre interioridade e exterioridade, hoje quase ausentes da formação e da prática docente (BERNSTEIN, 1998). Proponho, ainda, que a formação docente se torne uma conversação instigante, cujo desenvolvimento possa intensificar a recuperação sugerida. Por conversação, refiro-me aos encontros que se desdobram nas escolas e nas salas de aula, pautados por diálogos densos, abertos, interessados e plenos de subjetividade (PINAR, 2003; 2004). Nessa conversação, reservo assento privilegiado para a teoria de currículo e suas pertinentes análises sobre os processos de seleção e de organização do conhecimento escolar.

É importante que se discuta com os professores, convocados a ensinar as diferentes disciplinas, o espírito que as deve animar. No currículo da formação docente, há que se reservar significativo espaço para que se avaliem as escolhas referentes ao que e como ensinar, que se apreciem suas razões e as necessidades a que visam a atender. Deve-se, assim, familiarizar os futuros docentes com os problemas para os quais os conteúdos curriculares pretendem oferecer soluções provisórias. $\mathrm{Ou}$ seja, é essencial iniciá-los nos grandes desafios a serem enfrentados pela Educação na sociedade. É essencial que os professores selecionem e ensinem conteúdos significativos, capazes de facilitar ao estudante

melhor se situar no mundo em que vive e perceber as situações agressivas a que muitos indivíduos e grupos estão submetidos por fatores relacionados a classe, raça e gênero. A intenção é propiciar a compreensão de que essas situações não são inevitáveis e podem ser transformadas (MOREIRA; MACEDO, 2001, p. 123). 
Em outras palavras, o que se pretende é "promover uma Educação que garanta a apropriação de conhecimentos, habilidades e visões de mundo que se mostrem indispensáveis para poder viver, conviver, lutar e sobreviver no mundo contemporâneo" (MOREIRA, 2013, p. 547).

Vale acrescentar que participar da escola implica saber como esta se estrutura e como funciona. Correspondendo ao principal ambiente de trabalho do professor, faz-se indispensável entendê-la, analisar seu passado, seu presente, assim como suas possibilidades futuras. Mas não é suficiente conhecer as leis que definem sua forma e sua organização. Há que se compreender suas motivações, suas metas, sua vida interna, suas normas, seus movimentos, suas contradições, suas possibilidades. Em síntese, entender as forças que movem tanto a escola quanto as disciplinas curriculares requer situá-las na cultura, na história, na política, na instituição e na subjetividade. Eis, com certeza, um importante desafio para os que pensam e organizam os currículos na formação de professores.

Defendo, assim, a necessidade de se estimular, junto ao profissional do magistério, a crítica da escola e das disciplinas. Daí a pertinência do estudo de teorias de currículo, tema que carece, a meu ver, de maior destaque na formação docente. Há que se oferecer ao professor uma formação em que o conhecimento apreendido ativamente, bem como as experiências vivenciadas, promovam o desenvolvimento de uma identidade que se construa, dominantemente, a partir do interior, de forma relativamente independente das leis do mercado e do consumo (BERNSTEIN, 1998). É essa a perspectiva que desejo destacar no texto que lhes apresento.

Ao desenvolvê-lo, examino continuidades e descontinuidades entre interioridade e exterioridade. A seguir, argumento a favor de uma escola e de uma formação docente que configurem espaços de crítica e de humanismo. Sustento, ainda, que se faça da teoria de currículo significativo objeto de estudo e análise nos cursos de formação. Nas considerações finais, esforço-me por reunir as principais linhas de argumentação desenvolvidas ao longo do texto, alertando contra o perigo implicado na formação de um profissional "sem atributos" (MUSIL, apud LUCKMANNN, 2007).

\section{A interioridade e a exterioridade na formação docente}

Como já acentuou-se (BERNSTEIN, 1998), o princípio do mercado, vigente no mundo contemporâneo, tem gerado uma notável cisão entre quem conhece e o que é conhecido, provocando a formação de dois mercados independentes - um dos criadores e usuários do conhecimento e outro do próprio conhecimento. Essa descontinuidade acaba desconectando o interior do exterior, em consonância com os princípios do mercado pautados no neoliberalismo. 
Contrapondo-me a essa abordagem, sugiro, mais uma vez, que a formação de professores preserve, em seu currículo, a articulação entre interioridade e exterioridade, ou, em outros termos, entre a relação do docente com o seu próprio eu e a sua relação externa com o mundo. Vejo-as, agregadas, conformando a identidade dos professores como seres sociais e membros da sociedade e, mais especificamente, como membros autônomos e competentes de um grupo profissional (YOUNG, 2008). Daí a necessidade de que o conhecimento, na formação de professores, corresponda à expressão externa de uma relação interior.

A primeira ruptura na continuidade do conhecimento oficial parece ter ocorrido no período medieval (DURKHEIM, 1977). Naquela ocasião, tornou-se notória a descontinuidade entre o trivium e o quadrivium, significativamente distinta da que hoje se verifica. Para entender essa diferença e defender meu ponto de vista, recorro, então, a Bernstein (1998), bem como à sua leitura de Durkheim (1977).

Em seu estudo do desenvolvimento da Educação Secundária na França, Durkheim caracteriza a Educação na antiguidade clássica, antes de tudo, por seu enciclopedismo. A totalidade do conhecimento humano, vista como necessária para que o Ensino fosse, de fato, educativo, se apresentava, então, sob a forma de sete disciplinas as sete artes liberais -, divididas em dois grupos, cujos significados educacionais eram distintos entre si e variaram ao longo da Idade Média. Ensinava-se primeiro o trivium (gramática, retórica e dialética), que incluía o conhecimento comum, o conhecimento plebeu, e, a seguir, o quadrivium (aritmética, astronomia, geometria e música), que representava o conhecimento reservado a uma elite de especialistas. O trivium correspondia à exploração da palavra, ao passo que o quadrivium à exploração do mundo, associados, ambos, pela unidade do cristianismo.

Por meio do trivium se instruía a mente sobre si própria, isto é, dava-se a conhecer as leis a que obedecemos quando pensamos e quando nos expressamos, assim como as regras que devemos seguir para pensarmos e nos expressarmos corretamente. $\mathrm{O}$ quadrivium consistia de uma série de ramos do conhecimento relacionados com as coisas. Visava a favorecer a compreensão das realidades externas e das leis que as governam. Em última análise, o trivium buscava configurar a inteligência, ao passo que o quadrivium pretendia preenchê-la, nutri-la.

Complementando a interpretação de Durkheim, Bersntein acentua que, no caso do trivium, mais do que da palavra, tratava-se da compreensão dos princípios a ela subjacentes. Do mesmo modo, no quadrivium, mais do que propriamente para o mundo, o foco se dirigia para os princípios necessários à sua compreensão. Por isso, estudava-se o trivium e depois o quadrivium. 
Ainda conforme Bernstein, com o trivium criava-se uma determinada forma de consciência, uma modalidade característica do eu: buscava-se estabelecer limites a essa forma de consciência, regulando o eu. A meta era, então, a construção do interior, condição prévia para a compreensão do exterior, do mundo.

Nessa seqüência pedagógica (a palavra precedendo o mundo), a interioridade e o compromisso configuravam os termos do engajamento prático com o mundo, o que corresponderia às origens das profissões. Pode-se considerar que o comprometimento profissional, bem como o senso de dedicação a ele associado, resultariam, ao menos em parte, da separação da palavra e do mundo (YOUNG, 2008).

No período medieval, havia, assim, dois discursos especializados distintos: um para a construção do interior e outro para a construção do exterior. Nos séculos seguintes, o fundamento religioso do conhecimento oficial foi progressivamente substituído por um princípio humanista secular. No momento atual, em muitas situações, os princípios do mercado e da economia converteram-se no critério orientador da seleção dos discursos, de suas vinculações, de suas formas e, mesmo, de sua investigação. Uma das conseqüências tem sido a crescente insistência em destrezas básicas mensuráveis (na escola fundamental), em especializações profissionais (no Ensino Médio) e em uma falsa descentralização e novos mecanismos de controle estatal (na Educação Superior e na pesquisa).

O conhecimento termina por encaminhar-se para direções em que proporcione vantagens e benefícios. O conhecimento divorcia-se do interior e das diretrizes humanistas que deveriam inspirá-lo. Alienando-se o conhecimento da interioridade, do compromisso, do esforço pessoal, da estrutura profunda do eu, faz-se possível trocar as pessoas de posições, substituir umas por outras, assim como excluí-las do mercado. Porém, concebendo-se o conhecimento como a expressão externa de uma relação interior, pode-se garantir sua legitimidade, sua integridade, sua dignidade, bem como o status de quem conhece. É essa última perspectiva que gostaria de ver pautando os cursos de formação docente.

Abordando-se a formação com base na articulação entre interioridade e exterioridade, na associação entre o conhecimento e o sujeito que conhece, na visão da ação docente como a expressão de uma relação interior, pode-se refletir mais profundamente sobre aspectos que devem marcá-la. Entre eles, reitero a necessidade de se conceber a prática do professor como atividade intelectual, bem como a premência de se incluir reflexões sobre o currículo nos cursos de formação. Sustento, então, que o questionamento do existente (tarefa nuclear da 
função intelectual), bem como a análise de questões relativas ao conhecimento escolar (à sua construção, à sua seleção, à sua organização e ao seu Ensino), quando presentes na formação docente, catalisam o desenvolvimento da interioridade indispensável ao exercício da docência. No processo, a formação docente e a escola conformam-se como espaços de crítica e de humanismo.

\section{A crítica e o humanismo na formação docente}

Em texto anterior (MOREIRA, 1995), Giroux (1988) auxiliou-me a acolher a perspectiva do professor como intelectual transformador. Desejo enriquecê-la com considerações de Sarlo (1999; 2001) sobre o papel dos intelectuais na contemporaneidade. Apoiando-me na autora, passo a argumentar a favor de se transformar a escola em um espaço de crítica cultural, em um espaço de questionamento do existente. Recorro, inicialmente, às suas agudas observações sobre a situação de seu país nos anos 1990.

Estamos no fim do século e na Argentina. Luzes e sombras definem uma paisagem conhecida no Ocidente. Todavia, os contrastes aqui se exageram, por duas razões: nossa marginalidade em relação ao Primeiro Mundo [...] e a dura indiferença com que o Estado entrega ao mercado a gestão cultural sem procurar institucionalizar uma política de compensação. Como outras nações da América, a Argentina vive o clima do que se chama "pós-modernidade" no marco paradoxal de uma nação fraturada e empobrecida. Vinte horas de televisão diariamente, por cinqüenta canais, e uma escola desamparada, sem prestígio simbólico nem recursos materiais; paisagens urbanas traçadas segundo o último design do mercado e serviços urbanos em estado crítico (SARLO, 2001, p. 7).

A autora opõe-se, vigorosamente, à crescente homogeneização cultural, bem como à situação paradoxal em que se convive tanto com uma variada oferta de bens a serem consumidos (e uma suposta liberdade de escolha), quanto com uma lastimável carência de ideais coletivos e com um intenso individualismo. Nesse contexto, a meta maior passa a ser a satisfação de necessidades artificialmente criadas, elevada à condição de ato de liberdade e de diferenciação.

Sarlo (2001) indica possíveis saídas para tal panorama, mais a partir de perguntas que favoreçam o ver do que a partir de perguntas que definam estratégias e receitas para uma ação imediata, pré-definida. Assim, perguntas referentes a como alcançar uma perspectiva para se ver são mais pertinentes do que perguntas referentes ao que fazer. A atividade intelectual define-se, então, pelo questionamento do que 
parece inscrito na natureza das coisas, do que é apresentado como natural. Esse questionamento visa, fundamentalmente, a mostrar que as coisas não são inevitáveis.

A atividade intelectual passa a centrar-se na crítica da cultura em que se está imerso. À variada gama de determinismos (determinismo técnico, determinismo de mercado, determinismo neopopulista) que marcam o cenário social. Sarlo (2001) contrapõe perguntas cuja intenção seja perturbar as justificativas, celebratórias ou cínicas, do existente.

A função crítica que, entre outras funções, os intelectuais têm desempenhado, exerce ainda poderoso apelo, por não se terem desvanecido as injustiças decorrentes de autoridade despótica e de concentração de riquezas. Ainda que a voz da crítica não pertença exclusivamente aos intelectuais, há, para eles, um dever, decorrente do saber, que se impõe, na sociedade, com elevada força moral. Para os intelectuais, a crítica do existente, o espírito livre e não conformista, a ausência de temor frente aos poderosos, bem como a solidariedade com as vítimas, têm constituído eixos propulsores de sua prática nos últimos séculos (SARLO, 1999).

Esse pensamento crítico é, por definição, autônomo. Autonomia e crítica, assim, se pressupõem: a exclusão de uma impede o desenvolvimento da outra (SARLO, 2001). A autonomia do pensamento crítico, no mundo ocidental, derivou, em parte, de complexas revisões das melhores tradições do pensamento progressista.

Sublinhar a autonomia do pensamento crítico não implica o abandono da política nem o desprezo pelas questões públicas. Pelo contrário, a prática intelectual crítica demanda uma relação tensa com a política, na qual o pensamento crítico resista à pressão dos interesses imediatos, sem, contudo, afastar-se dos problemas neles envolvidos. O pensamento crítico deve relacionar-se com a política, sem definirlhe suas bases de ação e sem dela receber a legitimação que ambos, política e discurso crítico, são capazes de adquirir, na sociedade, por seus próprios meios.

Faz sentido, com base nessas considerações, sugerir que, na escola, o professor, por meio das atividades curriculares, mostre ao aluno que as coisas não são inevitáveis, ajudando-o a compreender que a ordem social em que está inserido se conforma por ações sociais cujo poder não é absoluto: "o dado é a condição de uma ação futura, não seu limite" (SARLO, 1999, p. 10). Os questionamentos que se façam devem visar a perturbar, a provocar tensões. Podem não mudar o mundo, mas podem permitir que o aluno o compreenda melhor. Como nos diz Bauman (2001), "para operar no mundo (por contraste a ser 'operado' por ele) é preciso entender como o mundo opera" (p. 242). 
A crítica do existente inclui examinar o processo de construção de diferentes manifestações e artefatos culturais, para que se percebam as relações de poder neles expressas. Requer a identificação das relações assimétricas entre distintas culturas, de modo a propiciar tanto sua transformação como o estabelecimento de pontes entre elas. Implica, também, a desestabilização do caráter monocultural e da lógica eurocêntrica, que têm justificado a escolha dos conteúdos curriculares (cotejando-a com outras lógicas, com outras formas de ver o mundo). Nesse processo, o conhecimento escolar se redefine e se reorganiza, rompendo-se fronteiras e rearticulando-se saberes. A crítica do existente implica, em resumo, o questionamento da relação dos indivíduos com a natureza, com a cultura, com o conhecimento e com a sociedade.

A escola como espaço de crítica cultural não pode prescindir de um professor preparado para organizá-la, que tenha aprendido a fazê-lo em sua formação. Para isso, reitero, há que se transformar a formação docente em um espaço de crítica e de autonomia, no qual se desenvolva o humanismo necessário à interioridade que precede a leitura do mundo.

As análises de Said (2007) sobre o humanismo e a crítica democrática ampliam as reflexões até aqui apresentadas. Para o autor, o humanismo corresponde a uma práxis utilizável para intelectuais e acadêmicos que desejam saber o que estão fazendo, quais são seus compromissos como eruditos e, ainda, como conectar esses princípios ao mundo em que vivem como cidadãos. Não serão esses mesmos conhecimentos indispensáveis à atividade docente no mundo contemporâneo?

Como a mudança é parte essencial da história humana, e a história decorre da ação humana, só assim podendo ser compreendida, vale afirmar que o núcleo do humanismo se consolida na noção secular de que o mundo histórico é feito por homens e mulheres, não por Deus, e é passível de ser compreendido racionalmente. Só conhecemos, então, realmente, o que fazemos ou, em outras palavras, só podemos conhecer as coisas conforme o modo como foram feitas.

Conhecer é, assim, saber como algo foi construído, é considerá-lo com base no ponto de vista de seu criador humano. Daí a inegável capacidade do ser humano para criar conhecimento, em oposição a absorvê-lo de forma passiva, reativa e embotada, o que tem significativas implicações para a escola, a formação e a prática docentes.

As humanidades, ainda conforme Said, dizem respeito à história secular, aos produtos do trabalho humano, à capacidade humana de articular a expressão. 
Referem-se às coisas que não estão sujeitas a uma explicação adequada em termos das leis gerais dos processos naturais, físicos ou biológicos, ou em termos (apenas) de condições ou forças sociais coletivas. Referem-se, em suma, ao que comumente nos referimos como realizações humanas. O humanismo é, portanto, a realização da forma pela vontade e pela ação humanas. Não é nem um sistema nem uma força impessoal, como o mercado ou o inconsciente, por mais que se acredite no funcionamento de ambos. Pode, por conseguinte, contrapor-se ao atual processo de aquisição do conhecimento, desumanizado e subordinado ao mercado, no qual interioridade e exterioridade se separam.

Compreender o humanismo é concebê-lo como democrático, aberto, portanto, a todas as classes e formações. É entendê-lo como um processo de revelação, de descoberta, de autocrítica e de liberação. É visualizá-lo como um processo em que cada vez mais coisas se tornam acessíveis ao escrutínio crítico: o produto do trabalho humano, as energias humanas mobilizadas para a emancipação e para o esclarecimento, bem como as leituras e as interpretações humanas errôneas do passado e do presente. Há sempre que se desmascarar, entender e criticar toda injustiça, todo castigo coletivo cruel, todo plano de dominação, todo gesto de discriminação e de opressão.

Cada leitura e cada interpretação de uma obra clássica irão reanimá-la no presente, fornecendo uma ocasião para que o moderno e o novo situem-se em um amplo campo histórico, cuja utilidade é nos mostrar a história como um processo que ainda está sendo feito, em vez de terminado e decidido de uma vez por todas. Trata-se de perceber que a história humana é um processo contínuo de autoanálise e autorrealização. Faz-se necessário, portanto, considerar que há sempre outras tradições eruditas no mundo, sempre outras culturas, sempre outras histórias, sempre outros gênios. O que faz as culturas interessantes não é nem sua essência, nem sua pureza, mas, sim, suas combinações, sua diversidade, sua contracorrente, seus diálogos imperiosos com outras culturas (SAID, 2007). Cabe, então, à escola e à formação docente, atuar de modo a favorecer ao estudante o emprego de suas faculdades linguísticas para compreender, reinterpretar e lutar com os produtos da linguagem na sua história, em outras línguas e em outras histórias.

O que caracterizam a erudição, a leitura e a interpretação humanistas é a capacidade de desemaranhar o habitual do não habitual, o ordinário do extraordinário nas obras estéticas, bem como nas afirmações e decisões de intelectuais e de políticos. O humanismo implica resistência a toda idéia recebida pronta, assim como a todo tipo de clichê e de linguagem sem reflexão. Reitera-se, com base nessa argumentação, a defesa da escola e da formação docente como espaços de questionamento e de pesquisa. 
No núcleo do humanismo está a crítica, sempre inquietantemente reveladora, sempre em busca de liberdade, de esclarecimento, de mais ação. O humanista, por conseguinte, jamais se conforma com os horizontes e os confinamentos predominantes, buscando, permanentemente, desestabilizá-los. Em um cenário marcado por intensas, inusitadas e freqüentes transformações e reconfigurações, $o$ humanismo é e precisa ser um denso e consistente espaço de crítica, de perturbação, de investigação. O mesmo pode ser dito da escola e da formação docente.

\section{A teoria de currículo na formação docente}

Para o desdobramento de atividades de crítica e de investigação na escola e na formação docente, o estudo de teorias de currículo pode ser útil. Sugiro que uma das mais adequadas à recuperação dos elos entre interioridade e exterioridade e à consolidação da crítica e do humanismo é a teorização cujo núcleo se delineia como a compreensão do processo curricular (PINAR, 2004). Essa teorização emergiu, no campo do currículo, logo após o esgotamento do modelo do desenvolvimento curricular, hegemônico por cerca de cinqüenta anos.

Nessa tendência, a teoria de currículo deve propiciar uma maior compreensão do significado e dos rumos das disciplinas escolares e dos temas interdisciplinares, explicitando suas relações com o indivíduo, com a sociedade e com a história. Essa teoria não pretende oferecer subsídios para reformas curriculares inspiradas no mundo dos negócios, que enfatizem testes e exames padronizados, verdadeiros análogos acadêmicos da linha de montagem. Pode, contudo, facilitar a íntima associação entre o conhecimento e o sujeito que o aprende e o ensina, pretensão, sem dúvida, pertinente na formação de professores.

Na teorização em pauta, a formação do docente é concebida como um engajamento prospectivo e como a prática de um estudo autorreflexivo e interdisciplinar, frequentemente localizado nas intersecções do eu e da sociedade, do local e do global, das disciplinas escolares e da vida cotidiana. Por meio desse estudo, espera-se desenvolver no docente o cultivo da independência da mente, da autorreflexão e da cultura interdisciplinar. Pretende-se propiciar, ainda, a apreciação das relações mutáveis e complexas entre a formação docente e o conhecimento escolar, entendidos ambos sob uma ótica humanista.

A profissão de ensinar exige que o professor, como intelectual, participe de forma colaborativa na escola, tanto nas práticas do cotidiano escolar quanto nas decisões referentes a conteúdos curriculares, estilos de Ensino e procedimentos de avaliação. Participar do planejamento coletivo da escola e de seu currículo exige ter consciência das múltiplas funções e do potencial da instituição escolar. 
Exige considerar o currículo como um projeto formativo, como uma construção partilhada de saberes (MORGADO, 2019). Nessa perspectiva, o estudo crítico de teorias de currículo confirma-se como imprescindível.

Segundo Pinar, o principal objetivo do currículo escolar é promover compreensão compreensão das relações entre o conhecimento acadêmico, a sociedade, a cultura, a autoformação individual e o momento histórico em que nos situamos. Essa compreensão tanto subsidia a obrigação ética de cuidarmos de nós mesmos e de nossos companheiros, quanto nos capacita a pensar e a agir com inteligência, sensibilidade e coragem tanto na esfera pública (como cidadãos comprometidos com a democracia) quanto na esfera privada (como indivíduos comprometidos com outros cidadãos). Em última análise, trata-se da compreensão necessária ao exercício da crítica.

Por fim, a visão do currículo como uma conversação instigante harmoniza-se com os pontos de vista até aqui defendidos. O termo conversação, no sentido empregado por Pinar $(2003$; 2004), e por mim aceito, ilumina o ponto de encontro para o qual convergem diversas enunciações presentes na comunicação humana. Não se trata de empreendimento planejado para produzir um lucro extrínseco nem de uma disputa em que haja um vencedor. A conversação demanda uma diversidade de vozes: diferentes discursos se encontram, se reconhecem e se relacionam, sem que nenhum seja imposto ao outro. A conversação requer uma autêntica presença humana. Nela, as diferenças nas vozes não significam distanciamentos em relação a alguma maneira ideal de falar: elas simplesmente diferem entre si. Na conversação, portanto, confluem diferentes modos de pensar, de imaginar e de improvisar.

As disciplinas escolares também constituem conversações: denotam um constante e intenso debate sobre significativos aspectos do conhecimento e da experiência humana. São tradições vivas, correspondem ao conhecimento em ação. Por meio delas, os alunos tornam-se familiares com diferentes expressões, culturalmente significativas, desse conhecimento.

Insisto, então, em que a teoria de currículo, particularmente a abraçada por Pinar, constitua objeto de Ensino nos cursos de formação de professores. Vejo-a como instrumento capaz de incrementar os elos entre quem ensina e o que ensina; vejo-a, também, como alavanca da crítica e do humanismo na formação e na prática docente. Como o currículo é o núcleo organizacional e intelectual da escola, sua análise envolve os processos de seleção e organização do conhecimento, bem como o processo educativo em que professores e alunos se encontram imersos. Implica, ainda, interpretar os contextos em que se processa a construção de projetos de Educação e formação (PACHECO; MENDES; SOUSA, 2018). 


\section{Considerações finais}

Coloquei-me, no decorrer deste texto, a favor de uma formação docente em que se conceba o professor como um intelectual capaz de autonomia e de pensamento crítico. Acrescentei a essa perspectiva a concepção da escola como espaço significativo de desenvolvimento do humanismo e da crítica. Assim entendidas, as atividades docentes e escolares podem, ao menos em algum grau, contribuir para que se enfrentem os desafios vividos pela escola brasileira no atual cenário, que se pauta por cruciais mudanças, desenvolvimento tecnológico sem precedentes, acentuada crise de valores e de paradigmas, novas e tensas configurações geográficas e políticas, riscos ambientais, ataques terroristas, xenofobia, preconceitos, discriminações, desigualdades sempre mais acentuadas. Nesse conturbado panorama, a escola brasileira é vista como em permanente crise, marcada por cruéis processos de exclusão e de fracasso de estudantes de grupos subalternizados e oprimidos.

Entre os complexos e numerosos fatores que respondem por esse persistente fracasso da escola brasileira, pode-se destacar uma formação docente também caracterizada por desafios não vencidos, por obstáculos que persistem em dificultar a concretização de transformações e a operacionalização de propostas inovadoras. Entretanto, já se acentuou que não carecemos de ideias e de teorias capazes de fundamentar os esforços dirigidos à renovação da formação, que se fazem cada vez mais urgentes e indispensáveis (FREITAS, 1992). Já se acentuou, também, o risco envolvido nas afirmativas que negligenciam o ponto de vista de que as profissões dependem de uma dada base de conhecimentos especializados. Chega-se mesmo a propor que a formação profissional praticamente se limite a responder às novas circunstâncias e aos interesses e demandas do mercado e dos empregadores. Rejeita-se apressadamente, nessa equivocada perspectiva, a necessidade de um conhecimento profissional elaborado, testado e renovado, dominantemente, no ambiente universitário, espaço por excelência de profissionalização, de investigação e de construção de novos saberes e novas tecnologias (YOUNG, 2008).

Se não nos foi possível ainda aplicar à formação docente os conhecimentos que já conseguimos produzir, sustento que continua válida a visão da atividade docente como prática em que se associam o político, o intelectual e o acadêmico. Reitero a visão dos cursos de formação docente e da escola como espaços de crítica e de pesquisa, norteados pelo humanismo que se faz necessário para impedir a subordinação da atividade e da formação docente à lógica do mercado e para evitar que se dissemine a dissociação entre a interioridade e a exterioridade, ou seja, entre a palavra e a leitura e a compreensão do mundo. Renovo, mais uma vez, a 
crença na importância do estudo do currículo, que talvez facilite a consolidação dos elos entre quem conhece e o que se conhece, bem como entre quem ensina e o que se ensina e o que se aprende na escola e na sala de aula.

Como argumentou Luckmann (2007), não mais circulam, nas sociedades contemporâneas, representações amplamente aceitas do que se julga ser uma identidade adequada. Como conseqüência, diferentes modelos de identidade buscam aproveitar o vazio, surgindo, assim, uma espécie de mercado de identidades. Entre essas, encontra-se a que acentua a autonomia do indivíduo e do profissional. Há, porém, um risco subjacente: a autonomia esboçar-se simplesmente como a capacidade de adaptação às rápidas e freqüentes mudanças na sociedade mais ampla e no trabalho. Em contraposição, então, há que se reforçar a centralidade de uma construção interior ainda dependente, em certo grau, de uma identificação participativa com dimensões identitárias de gênero, etnia, família, nação, religião e profissão. Adaptando expressão já clássica de Musil (apud Luckmann, 2007), ao tema abordado neste texto, urge impedir, a todo custo, que venhamos a formar um professor "sem atributos". 


\section{Teacher's training and curriculum: questions for debate}

\section{Abstract}

This article provides a theoretical analysis of the initial teacher training and its relationship with the curriculum. Based on the arguments raised, we seek to configure a conception of quality in school and in teacher training, analyzing the initial training comprehensively, in order to avoid partialities and fractions. As conclusions, it is pointed out that this training cannot be seen only as a practical activity, based on instrumental rationality, but as an intellectual activity, guided by the conscious exercise of criticism and by a humanist posture.

Keywords: Teacher training. Curriculum. Humanism.

\section{Formación de profesores y currículo: cuestiones en debate}

\section{Resumen}

Este artículo proporciona un análisis teórico de la formación inicial del profesorado y su relación con el currículo. Con base en los argumentos planteados, se busca configurar una concepción de calidad en la escuela y en la formación del profesorado, analizando la formación inicial de forma exhaustiva, a fin de evitar parcialidades y fracciones. Como conclusiones, se señala que este entrenamiento no puede verse solo como una actividad práctica, basada en la racionalidad instrumental, sino como una actividad intelectual, guiada por el ejercicio consciente de la crítica y por una postura humanista.

Palabras clave: Formación de Profesores. Currículo. Humanismo. 


\section{Referências}

BAUMAN, Z. Modernidade líquida. Rio de Janeiro: Jorge Zahar, 2001.

BERNSTEIN, B. Pedagogia, control simbólico e identidad. Madrid: Morata, 1998.

DURKHEIM, E. The evolution of educational thought: Lectures on the formation and development of secondary education in France. London: Routledge \& Kegan Paul, 1977.

FREITAS, L. C. Em direção a uma política para a formação de professores. Em Aberto, Brasília, DF, v. 12, n. 54, p. 3-22, abr./jun. 1992.

GIROUX, H. Teachers as intellectuals: toward a critical pedagogy of learning. Westport: Bergin \& Garvey, 1988. (Critical studies in educativo series).

LUCKMANN, T. Condiciones estruturales necesarias para la constitución de la identidad personal. In: DREHER, J. et al. (orgs.). Construcción de identidades em sociedades pluralistas. Buenos Aires: Lumiere, 2007.

MOREIRA, A. F. O currículo como política cultural e a formação docente. In: SILVA, T. T.; MOREIRA, A. F. (orgs.). Territórios contestados: o currículo e os novos mapas políticos e culturais. Petrópolis: Vozes, 1995. p. 7-20.

MOREIRA, A. F. Currículo e gestão: propondo uma parceria. Ensaio: Avaliação e Políticas Públicas em Educação, Rio de Janeiro, v. 21, n. 80, p. 547-562, jul./set. 2013. https://doi.org/10.1590/S0104-40362013000300009

MOREIRA, A. F.; MACEDO, E. F. Em defesa de uma orientação cultural na formação de professores. In: CANEN, A.; MOREIRA, A. F. B. (orgs.). Énfases e omissões no currículo. Campinas: Papirus, 2001. p. 117-145.

MORGADO, J. C. Currículo e educação comparada: perspectivas e desafios. Revista Teias, Rio de Janeiro, v. 20, n. 57, p. 12-19, 2019. https://doi.org/10.12957/teias.2019.40262

PACHECO, J. A.; MENDES, G. M. L.; SOUSA, J. R. F. O conhecimento escolar em termos de uma pluralidade de saberes e novas formas de aprendizagem. Educação Unisinos, São Leopoldo, v. 22, n. 4, p. 268-277, out./dez. 2018. https://doi.org/10.4013/edu.2018.224.04

PINAR, W, F. A equivocada educação do público nos Estados Unidos. In: GARCIA, R. L.; MOREIRA, A. F. B. (orgs.). Currículo na contemporaneidade: incertezas e desafios. São Paulo: Cortez, 2003. p. 139-157. 
PINAR, W. F. What is curriculum theory? Mahwah: Lawrence Erlbaum Associates, 2004.

SAID, E. Humanismo e crítica democrática. São Paulo: Companhia das Letras, 2007.

SARLO, B. Escenas de la vida posmoderna: intelectuales, arte y videocultura em la Argentina. Buenos Aires: Ariel, 1999.

SARLO, B. Tiempo presente: notas sobre el cambio de una cultura. Buenos Aires: Siglo Veintiuno, 2001.

YOUNG, M. F. D. Bringing knowledge back in: from social constructivism to social realism in the sociology of education. London: Routledge, 2008.

\section{Informações sobre o autor}

Antonio Flavio Barbosa Moreira: Doutor em Educação pelo Instituto de Educação da Universidade de Londres. Professor Emérito da Universidade Federal do Rio de Janeiro. Professor titular da Universidade Católica de Petrópolis. Pesquisador 1A do CNPq. Contato: afmcju@gmail.com

iD https://orcid.org/0000-0001-7097-0238 